\title{
A educação ambiental promovendo saúde no ambiente escolar: uma revisão bibliográfica
}

\author{
Environmental education promoting health in the school environment: a literature review
}

Educación ambiental que promueve la salud en el entorno escolar: una revisión de la literatura

Lázaro Saluci Ramos ${ }^{1 *}$, Soraia Jordão Souza ${ }^{2}$, Marilene da Silva Reis Barreto², Jociele Moreira Gomes $^{2}$, Cheila dos Santos Marvila², Adriano Gomes Santos², Celso Faria dos Santos², Fernanda da Silva Gomes², Jaqueline da Cunha², Maria Aparecida Terra Tonon².

\section{RESUMO}

Objetivo: A proposta desta revisão é reunir a bibliografia que trata a educação ambiental como alternativa para melhorar a qualidade de vida da população. A revisão propõe uma análise profunda acerca dos benefícios de cuidar do meio ambiente e como esses cuidados podem gerar efeitos benéficos à saúde. Revisão bibliográfica: A saúde do ser humano, o aumento da expectativa de vida e as condições que possibilitam uma vida mais saudável, passam indispensavelmente pelas questões ambientais. $O$ equilíbrio do meio ambiente posiciona todos os recursos necessários para que o ser humano cuide com mais responsabilidade da sua saúde. Entretanto, as questões ambientais não recebem os devidos espaços e sua importância ainda é questionada, pela ausência de provas da sua eficácia no campo físico. Explorar o ambiente escolar, e garantir conhecimento pleno acerca de políticas ambientais, fará com que as futuras gerações produzam políticas de saúde com ações ambientais. Considerações finais: $O$ estudo aponta experiências e uma bibliografia vasta como incentivo ao desenvolvimento de uma educação ambiental estratégica, que esteja atrelada as necessidades da saúde do ser humano.

Palavras-chave: Educação e saúde, Saúde e meio ambiente, Saúde na escola.

\section{ABSTRACT}

Objective: The purpose of this review is to gather the bibliography that deals with environmental education as an alternative to improve the quality of life of the population. The review proposes an in-depth analysis of the benefits of caring for the environment and how that care can generate beneficial health effects. Bibliographic review: The health of the human being, the increase in life expectancy and the conditions that enable a healthier life, pass through the environmental issues. The balance of the environment places all the necessary resources for the human being to take more responsibility for their health. However, environmental issues do not receive adequate space and their importance is still questioned, due to the lack of evidence of their effectiveness in the physical field. Exploring the school environment, and ensuring full knowledge about environmental policies, will make future generations produce health policies with environmental actions. Final considerations: The study points out experiences and a vast bibliography as an incentive to the development of a strategic environmental education, which is linked to the human health needs.

Key words: Education and health, Health and environment, Health at school.

\section{RESUMEN}

Objetivo: El propósito de esta revisión es recopilar la bibliografía que aborda la educación ambiental como una alternativa para mejorar la calidad de vida de la población. La revisión propone un análisis en profundidad de los beneficios del cuidado del medio ambiente y cómo esa atención puede generar efectos beneficiosos para la salud. Revisión bibliográfica: La salud del ser humano, el aumento de la esperanza de vida y las condiciones que permiten una vida más saludable, pasan por los problemas ambientales. El equilibrio del medio ambiente coloca todos los recursos necesarios para que el ser humano asuma más responsabilidad por su salud. Sin embargo, los problemas ambientales no reciben un espacio adecuado y su importancia aún

\footnotetext{
${ }^{1}$ Faculdade Multivix (MULTIVIX), Cachoeiro de Itapemirim - ES. *E-mail: lazaro321123@gmail.com

${ }^{2}$ Faculdade Vale do Cricaré (FVC), São Mateus - ES.
} 
se cuestiona, debido a la falta de evidencia de su efectividad en el campo físico. Explorar el entorno escolar y garantizar el pleno conocimiento de las políticas ambientales hará que las generaciones futuras produzcan políticas de salud con acciones ambientales. Consideraciones finales: El estudio señala experiencias y una vasta bibliografía como incentivo para el desarrollo de una educación ambiental estratégica, que esté vinculada a las necesidades de salud humana.

Palabras clave: Educación y salud, Salud y medio ambiente, Salud en la escuela.

\section{INTRODUÇÃO}

A educação ambiental se destaca em inúmeros campos na busca por uma sociedade mais sustentável e equilibrada. Como instrumento de inovação social, os cuidados com o meio ambiente se destacam em inúmeras políticas públicas. As políticas educacionais, por exemplo, quando o aluno é inserido em projetos que contemplam o contato com o meio ambiente, ele é exposto a uma nova realidade. Há que considerar que o futuro da humanidade está fadado ao controle ambiental e a preservação, por isso é importante inserir a educação ambiental como forma de contemplar as necessidades futuras e preparar as futuras gerações para as demandas que estão a seguir (PICCOLI AS, et al., 2016).

Uma análise séria, contemplativa e bem estruturada, poderá apontar o fundo ambiental em quase todos os problemas sociais. Quando o desequilíbrio do meio ambiente está acentuado, naturalmente outras estruturas da sociedade entram em colapso. O elo que liga a conservação do meio ambiente ao equilíbrio das estruturas sociais é justamente a necessidade do bem estar humano para que a máquina que move a sociedade consiga prosseguir. É inimaginável uma sociedade adoecida fisicamente, alcançando produtividade e desenvolvimento. Com o aumento do número de áreas afetadas pelo desmatamento e pela exploração desenfreada do homem, catástrofes, hecatombes e doenças são dispensadas a sociedade (BESERRA EP, et al., 2010).

A consciência ambiental é despertada no ser humano a partir do momento que ele é inserido no contexto proposto. A causa ambiental de fato foi tratada com importância a partir do século $X X$, antes disso, foram milênios de exploração e desmatamento, explorações inconsequentes que resultaram em um total desequilíbrio. Boa parte dessa ação irresponsável se deve aos interesses econômicos, mas não pode ser descartada a responsabilidade construída através da ausência do conhecimento. Muito pouco se falou a respeito da preservação do meio ambiente quando o único interesse era explorar e ampliar territórios. Construir uma ponte entre o conhecimento e a consciência ambiental, é produzir ação responsável e uma sociedade mais inclinada a preservação (DEMOLY KRA e DOS SANTOS JSB, 2018).

Para Bonotto DMB e Carvalho MBSS (2016), a criança e o adolescente são mais suscetíveis ao saber, já que estão adquirindo o conhecimento que vai molda-los para a vida. A educação ambiental como instrumento de modificações sociais no futuro é o caminho mais promissor quando atentamos a importância de as futuras gerações estarem inseridas na preservação e conservação da plataforma verde do planeta. Quando se elenca a falta de consciência ambiental como principal fator permissivo da destruição do meio ambiente, as soluções surgem com a necessidade de incluir o tal conhecimento no cotidiano dos cidadãos. Despertar o aluno para a importância de tal conhecimento é uma forma de passar a responsabilidade de maneira saudável e sadia, dos cuidados com a natureza.

Os efeitos de um ambiente verde destruído, podem ser dos mais variados tipos. Uma preocupação pouco citada, mas muito pertinente, são as consequências da degradação do meio ambiente na saúde dos seres humanos. A filtragem do ar feita pelas árvores e pelos oceanos, é altamente comprometida quando esses ambientes estão sob risco. Não somente a derrubada de florestas, mas a poluição dos oceanos, estão crescendo em uníssono com o aumento contínuo dos problemas respiratórios.

A diminuição dos espaços dos animais nas florestas, faz com que eles passem a frequentar, cada dia mais, os ambientes urbanizados, aproximando os seres humanos de doenças desconhecidas. A agricultura familiar, pouco incentivada, em regiões muito populosas, também leva ao consumo de produtos industrializados, que não fornecem benefícios a saúde, além do consumo de alimentos pouco seguros (RIBEIRO H, et al., 2017). 
O propósito deste exame bibliográfico está em conduzir alternativas ambientais através da educação ambiental como porta para disseminar a importância de cuidar do meio ambiente, além de fazer a correlação entre o avanço das ações devastadoras e o aumento do comprometimento da saúde do ser humano. Qual a relação real entre depredação do meio ambiente e as dificuldades encontradas pelo ser humano para manter a vida sob perfeito equilíbrio? O fundo de tudo está intimamente ligado as consequências de uma vida levada sem aprimorar as práticas sustentáveis, e sem introduzir para as futuras gerações a importância de estar em harmonia com a fauna e flora, sejam elas terrestres ou marinhas.

\section{REVISÃO BIBLIOGRÁFICA}

A educação ambiental no Brasil está inserida nas disciplinas básicas relacionadas a saúde. Na educação básica, a disciplina de Ciências no ensino fundamental I e II e no ensino médio nas disciplinas de Biologia, Química e Física. Desde da estrutura e formação verde, a biologia animal até os componentes encontrados e desenvolvidos com matéria prima natural. A importância da preservação e conservação da fauna e da flora é tratada, de certa maneira, com frieza e com pouca ênfase nas suas importâncias, entretanto, após a inclusão desse campo na grade educacional, nota-se o crescimento constante do interesse no meio ambiente. Não se pode desprezar as campanhas publicitárias e o engajamento de ambientalistas em difundir suas causas e expressar sua importância (FRAGOSO E e NASCIMENTO ECM, 2018).

Qual o método utilizado nas escolas para incluir o aluno na causa ambiental e desperta-lo a importância de preservar, consumir e não destruir? Se a lógica do mercado capitalista continuar sendo difundida como única alternativa aos discentes, certamente a sustentabilidade e a preservação continuarão sendo colocadas como assuntos secundários. O aluno ser preparado para ser inserido no mercado de trabalho, é o costume mais comum do sistema educacional brasileiro. Muito comum ouvir incentivos apenas da importância de estar ganhando bem, ou de ser reconhecido socialmente, mas muito pouco se ouve incentivar da importância de levar uma vida cuidadosamente prática sem desprezar as necessidades humanas e promover bem estar social (STOTZ EM, 2014).

As consequências físicas para a depredação do meio ambiente, muito pouco divulgadas, são as reais causas do alastramento de doenças e da precarização da saúde humana. Quando um alimento é produzido com importância apenas para a quantidade e não para a qualidade, muitos componentes tóxicos são lançados no meio ambiente e na mesa do cidadão. A inconsequente colonização do globo terrestre, não só aumentou o alastramento de doenças, como potencializou seus desenvolvimentos e mutações.

Muito se deve também a derrubada de florestas e a extinção de animais que mantinham o equilíbrio do ecossistema. O mosquito aedes aegypti foi trazido para a América nos navios que traziam escravos do continente africano, em consonância com existência de doenças em animais, iniciou-se a contaminação de seres humanos. Tudo isso devido a ausência de conhecimento científico básico, e a ausência de preocupações com o meio ambiente (SOUZA C L e ANDRADE SC, 2014).

As formações na área ambiental ainda são pouco difundidas e possuem um campo muito pequeno no mercado de trabalho, o que reduz o interesse e não potencializa as pesquisas e desenvolvimento científico na área. Apesar de ser a principal fonte da extração de medicamentos e tratamentos para doenças, a natureza ainda não foi mapeada e explorada corretamente. $O$ extrativismo em regiões verdes surgiu como alternativa para frear o desmatamento e garantir o consumo de produtos fornecidos pelo meio ambiente. Quando as curas de enfermidades são localizadas em plantas, corpos ou produtos, é perceptível o quanto o meio ambiente é completo e favorável a condução da vida, entretanto, quando parte do seu seio é depredado, partes indispensáveis a continuidade da vida são destruídas, gerando consequências imprevisíveis (QUEVEDO CMG e PAGANINI WS, 2011).

Tornar o ambiente escolar um centro de referência para a educação ambiental, além de instruir as futuras gerações da importância de participar da construção de uma sociedade mais consciente, tornará a sociedade mais próxima da preservação, e colocará no cotidiano do ser humano propiciando mais interesse, que proporcionará ampliação de pesquisa, desenvolvimento de táticas sustentáveis, construção de bases verdes como indispensáveis ao prosseguimento da vida humana. 
A qualidade e a expectativa de vida se baseiam nas condições genéticas, alimentares e ambientais. O ser humano com uma alimentação livre de produtos químicos, está menos suscetível ao desenvolvimento de doenças, e a única forma de tornar a produção orgânica uma prioridade, é inteirando toda sociedade dos riscos que alimentos não-orgânicos trazem, além de tornar um hábito os cuidados alimentares e ambientais (MEDEIROS AB, et al., 2011).

\title{
Os benefícios da educação ambiental
}

Dentre as inúmeras políticas ambientais desenvolvidas nas últimas décadas, certamente a mais eficaz está relacionada a recuperação de áreas degradadas e a preservação da fauna silvestre. Além da difícil movimentação de recursos para ampliar políticas de preservação, o movimento verde conta com uma forte oposição do setor agro. Além da grande influência que grandes agropecuaristas possuem nas casas do Congresso Nacional, ainda existe a possibilidade de burlar a lei através de propinas ou brechas deixadas pela legislação vigente. De acordo com a Lei 9.605 do ano de 1998, que dispõe sobre as sanções penais e administrativas derivadas de condutas e atividades lesivas ao meio ambiente, há penas para quem comete crimes ambientais, mas nem sempre elas surtem os efeitos desejados, ou conseguem conter a devastação (RATTNER H, 2009).

\begin{abstract}
A lei dispõe que: Art. 38. Destruir ou danificar floresta considerada de preservação permanente, mesmo que em formação, ou utilizá-la com infringência das normas de proteção: Pena - detenção, de um a três anos, ou multa, ou ambas as penas cumulativamente. Parágrafo único. Se o crime for culposo, a pena será reduzida à metade. Art. 38-a. Destruir ou danificar vegetação primária ou secundária, em estágio avançado ou médio de regeneração, do Bioma Mata Atlântica, ou utilizá-la com infringência das normas de proteção: Pena - detenção, de 1 (um) a 3 (três) anos, ou multa, ou ambas as penas cumulativamente. Parágrafo único. Se o crime for culposo, a pena será reduzida à metade. Art. 39. Cortar árvores em floresta considerada de preservação permanente, sem permissão da autoridade competente: Pena detenção, de um a três anos, ou multa, ou ambas as penas cumulativamente (BRASIL, 1998).
\end{abstract}

O objetivo central de instruir as gerações futuras no processo de conservação e recuperação do meio ambiente, é uma alternativa promissora, que garante a expectativa de que no futuro teremos um ambiente sustentável e saudável para o desenvolvimento da vida humana. A expectativa de vida do ser humano está em constante crescimento e isso também se deve ao desenvolvimento científico. Entretanto, ainda não temos o contingente necessário de estudiosos engajados na prática ambiental, isso se dá pela pouca valorização da área e pelo baixo investimento estatal nas condicionantes que sustentariam o desejo de ter uma educação ambiental aceitável, como política social nas escolas públicas (LAMOSA RAC e LOUREIRO CFB, 2011).

A baixa fiscalização e a branda forma de lidar com crimes ambientais, fez com que a população não levasse em conta a responsabilidade que existe por detrás do desmatamento irregular. $O$ pouco desenvolvimento tecnológico fez também com que a fiscalização fosse limitada, o que já não é mais um problema tão grande.

Todavia, é cultural do brasileiro insistir no erro quando o crime é moralmente aceito. O crime ambiental foi socialmente aceito, já que não produz efeitos imediatos nem consequências aparentes. A falta de instrução social alimenta as atitudes insanas e inconsequentes, o que se caracteriza também um problema de comunicação. Mas como levar aos menos instruídos a importância de preservar o meio ambiente e garantir que saibam os efeitos que uma exploração desenfreada pode causar? Felizmente, o Brasil investiu firme na democratização do ensino e garantiu que a maior parte das crianças e adolescentes chegassem à escola (ASANO JGP e POLETTO RS, 2017).

Abrindo as portas da educação ambiental e ampliando os horizontes dos alunos para novas políticas da área, será possível dar continuidade a trabalhos de grandes ambientalistas como Chico Mendes, que foi assassinado por defender a causa ambiental na floresta amazônica. Chico Mendes foi um dentre os vários que deram a vida pela causa, mas ainda sim são poucos os que possuem coragem, tudo isso devido a baixa adesão e ao pouco interesse da população em se engajar. 
Provocar as gerações futuras e atentá-las para a necessidade de construir um muro humano ao redor das áreas de preservação, requer ampliar os horizontes da luta ambientalista. Tal atividade requer o esclarecimento do máximo de pessoas possível, e a vida escolar pode chegar a quase todos os lares. No entanto, o desenvolvimento estratégico ainda é frágil e falho (MENEZES DS e SIENA O, 2010).

Projetos escolares como os que levam os alunos aos biomas, incentivam a produção de alimentos orgânicos sem a utilização de agrotóxicos, que mostra o impacto da poluição e chama a atenção para a responsabilidade de não poluir e preservar, são caminhos fantásticos adotados por práticas contemporâneas. Levando para uma comparação metafórica, assim como em um balde de água suja que recebe uma forte corrente de água limpa, projeta-se a eliminação da sujeira, inserir na sociedade cidadãos conscientes das responsabilidades ambientais, vai limpar a cultura de devastação e conscientizar cada dia mais pessoas a tomar para si esta bandeira (DUTRA GKM e HIGUCHI MIG, 2018).

O contato do aluno com o meio ambiente, aumentará não só a consciência ambiental, mas ampliará de igual modo o número de pessoas interessadas em desenvolver pesquisas que colaborem, não somente para a proteção do meio ambiente, mas que intensifiquem as políticas de preservação e fiscalização, colaborando para mutação de uma cultura de exploração que existe desde a colonização. É comprovada a influência das futuras gerações na construção de uma sociedade mais adequada as necessidades impostas pelo progresso, e progredir hoje é necessariamente se atentar para as causas do meio ambiente (DUTRA GKM e HIGUCHI MIG, 2018).

\section{O direito fundamental à saúde através do direito ao meio ambiente}

A constituição da República de 1988 garante muitos direitos considerados essenciais e indispensáveis para a manutenção da vida humana. Dentre eles, o pouco conhecido direito ao meio ambiente. Se trata de um direito difuso e inviolável, protegido por norma na carta magna. Além do mais, o artigo 225 da Constituição Federal, garante e promove a proteção do meio ambiente em detrimento das necessidades humanas. Proteger as reservas ambientais, e garantir o equilíbrio do ecossistema, não somente atinge questões objetivas, mas é um elo direto com a proteção de um outro direito fundamental, o direito à saúde (SARLET IW e FENSTERSEIFER T, 2010).

É difícil imaginar nos tempos atuais, a defesa do direito fundamental à saúde desligada da conservação do meio ambiente. Países que não conseguem equilibrar seu ecossistema e não conteve o desmatamento, hoje correm atrás para reflorestar e retornar ao bioma original. Muitos países, como Dinamarca, Suécia e Islândia, que sofrem com mais potência os efeitos do aquecimento global, destinam recursos aos Países que protegem suas áreas verdes, como por exemplo o Brasil. Existe um grande interesse mundial em preservar a Amazônia, instintivamente o ser humano caminha para a defesa de um planeta habitável, e sem a conservação original do ambiente, fica cada vez mais difícil (PIASENTIN FB e GÓIS SLL, 2016).

Segundo um balanço publicado pela Fundação Oswaldo Cruz (Fiocruz) em outubro de 2019, o número de crianças internadas por síndrome respiratória praticamente dobrou em áreas de queimadas na Amazônia. Novamente um dado que aponta a necessidade da preservação ambiental para garantir a saúde da população. O Sistema Único de Saúde (SUS), registrou aproximadamente 30 mil internações, quando o esperado era 15 mil. Por mês passaram a ter 5 mil internações, um número muito acima da média nacional para regiões de alta umidade. Grande parte dos incêndios são causados por mãos humanas, e infelizmente uma enorme parcela acontece de forma criminosa, proposital, à fim de abrir espaço para atividades agropecuárias (FIOCRUZ, 2019).

A Constituição Federal de 1988 dispõe da seguinte maneira no Artigo 225, "Todos têm direito ao meio ambiente ecologicamente equilibrado, bem de uso comum do povo e essencial à sadia qualidade de vida, impondo-se ao Poder Público e à coletividade o dever de defendê-lo e preservá- lo para as presentes e futuras gerações", após, traz uma série de incisos e capítulos que complementam e posteriormente, as leis complementares ambientais que desenvolvem todo entendimento criado pelo legislador original (BRASIL, 1988).

Mudanças severas do clima do planeta, o aumento da temperatura média e muitos desastres ambientais, todos produzidos pela irresponsabilidade do homem. Os desastres criminosos nas barragens de Mariana e Brumadinho, são exemplos clássicos de como o poder financeiro pode e compra vidas todos os dias. A 
exemplo desses acontecimentos que produzirão efeitos longevos em rios e matas da região, existe o acidente nuclear na usina de Chernobyl no ano de 1986. A catástrofe, sem precedentes, poderia ter desertificado todo continente Europeu e talvez tornado o planeta Terra inabitável, tudo ocasionado por interesses pessoais de alguns, sem tratar o meio ambiente como direito indispensável e difuso (FREITAS CM, et al., 2019).

No mundo ainda existem inúmeras usinas nucleares, assim como no Brasil existem inúmeras barragens de exploração de minério. O ser humano, na busca por poder e dinheiro, é capaz de construir estruturas que podem dizima-lo a qualquer momento. Existe a cultura do risco e o esperar para agir, desde que o ser humano habita o planeta Terra.

A importância de preparar as futuras gerações para cuidar do meio ambiente e a modificação desta forma de agir é uma excelente opção para tirar o poder financeiro do primeiro plano e colocar os interesses coletivos a frente de qualquer expectativa individual. Só será possível compreender direitos coletivos, quando a preocupação for de fato o bem estar do coletivo, e para isso, é necessário que não se arrisque vidas, mas que elas sejam preservadas através de estruturas seguras de desenvolvimento (FREITAS CM, et al., 2019).

\section{CONSIDERAÇÕES FINAIS}

É perceptível o quão saúde e meio ambiente estão interligados. Um não existe sem o outro, e o equilíbrio de um garante o outro. Disseminar conhecimentos ambientais afim de preservar a saúde, só será possível através de uma revolução cultural e econômica, e esta revolução só pode começar com a preparação de pessoas que terão tempo e disposição para tais atos. A escola, é o ambiente mais propício para distribuir as novas expectativas e necessidades, os novos hábitos e conhecimentos, os novos meios e projetos que fará com que a vida possa continuar seguindo. O primeiro passo que foi a democratização do acesso a escola, já foi dado, agora resta inserir todo conhecimento que já se tem acerca de políticas ambientais e executar através ações efetivas, com um currículo também pautado no contato com os ambientes a serem protegidos, com atividades práticas e essenciais.

\section{REFERÊNCIAS}

1. ASANO JGP, POLETTO RS. Educação Ambiental: Em busca de uma sociedade sustentável, e os desafios enfrentados nas escolas. Revista Caderno Pedagógico, 2017; 14(1): 92-102.

2. BESERRA EP, et al. Educação ambiental e enfermagem: uma integração necessária. Revista Brasileira de Enfermagem, 2010; 63(5): 848-852.

3. BONOTTO DMB, CARVALHO MBSS. Educação Ambiental e valores na escola: buscando espaços, investindo em novos tempos. Ed online. São Paulo: Cultura Acadêmica, 2016; 175p.

4. BRASIL. 1998. In: LEI № 9.605, DE 12 DE FEVEREIRO DE 1998, dispõe sobre as sanções penais e administrativas derivadas de condutas e atividades lesivas ao meio ambiente, e dá outras providências. Brasil: Presidência da República. Disponível em: http://www.planalto.gov.br/ccivil_03/leis/l9605.htm. Acesso em: 28 de mai. 2020.

5. BRASIL. 1988. Constituição da República Federativa do Brasil: promulgada em 5 de outubro de 1988. CÂMARA DOS DEPUTADOS. 2019. In: AGÊNCIA CÂMARA DE NOTÍCIAS. Disponível em: https://www.camara.leg.br/noticias/110344-PROPOSTA-CRIA-PROGRAMA-DE-ORIENTACAO-SEXUAL-NASESCOLAS. Acesso em: 29 mai. 2020.

6. DEMOLY KRA, DOS SANTOS JSB. Aprendizagem, educação ambiental e escola: modos de en-agir na experiência dos estudantes e professores. Ambiente \& Sociedade, 2018; 1(21): 1-6.

7. DUTRA GKM, HIGUCHI MIG. Percepções ambientais de crianças que vivem em espaços degradados na Amazônia. Ambiente \& Sociedade, 2018; 21(1):1-7.

8. FIOCRUZ. 2019. In: PESQUISA mostra o impacto das queimadas na saúde infantil. São Paulo: Icict/Fiocruz. Disponível em: https://portal.fiocruz.br/noticia/pesquisa-mostra-o-impacto-das-queimadas-na-saude-infantil. Acesso em: 28 mai. 2020.

9. FRAGOSO E, NASCIMENTO ECM. Educação ambiental no ensino e na prática escolar da escola estadual Cândido Mariano - Aquidauana/MS. Ambiente \& Educação, 2018; 23(1): 161-184.

10. FREITAS CM, et al. Da Samarco em Mariana à Vale em Brumadinho: desastres em barragens de mineração e Saúde Coletiva. Cadernos de Saúde Pública, 2019; 35(5): 1-6.

11. LAMOSA RAC, LOUREIRO CFB. A educação ambiental e as políticas educacionais: um estudo nas escolas públicas de Teresópolis (RJ). Educação e Pesquisa, 2011; 37(2): 279-292.

12. MEDEIROS AB, et al. A Importância da educação ambiental na escola nas séries iniciais. Revista Faculdade Montes Belos, 2011; 4(1): 1-17.

13. MENEZES DS, SIENA O. Ambientalismo no Instituto Chico Mendes de Conservação da Biodiversidade (ICMBIO) na Amazônia legal. Organizações \& Sociedade, 2010; 17(54): 479-498. 
14. PIASENTIN FB, GÓIS SLL. Conservação de remanescentes florestais no Brasil: considerações sobre os principais instrumentos de gestão ambiental. Desenvolvimento e Meio Ambiente, 2016; 36(4): 115-134.

15. PICCOLI AS, et al. A educação ambiental como estratégia de mobilização social para o enfrentamento da escassez de água. Ciência \& Saúde Coletiva, 2016; 21(3): 797-808.

16. QUEVEDO CMG, PAGANINI WS. Impactos das atividades humanas sobre a dinâmica do fósforo no meio ambiente e seus reflexos na saúde pública. Ciência \& Saúde Coletiva, 2011; 16(8): 3532-3539.

17. RATTNER H. Meio ambiente, saúde e desenvolvimento sustentável. Ciência \& Saúde Coletiva, 2009; 14(6):19651971.

18. RIBEIRO H, et al. Alimentação e sustentabilidade. Estudos Avançados, 2017; 31(89): 185-198.

19. SARLET IW, FENSTERSEIFER T. Direito à saúde e proteção do ambiente na perspectiva de uma tutela jurídicoconstitucional integrada dos direitos fundamentais socioambientais (DESCA). BIS. Boletim do Instituto de Saúde (Impresso), 2010; 12(3): 248-253.

20. SOUZA CL, ANDRADE CS. Saúde, meio ambiente e território: uma discussão necessária na formação em saúde. Ciência \& Saúde Coletiva, 2014; 19(10): 4113-4122.

21. STOTZ EN. Educação Popular e Saúde e democracia no Brasil. Interface (Comunicação saúde educação), 2014; 18(2): 1475-1485. 